\title{
Photonic Crystal Fiber Sensor for X Ray Approximate Effective Radiation Dose
}

\author{
Raghad hani ${ }^{1}$, Ayad Z .Mohammed ${ }^{2}$, Bushra R.Mahdi ${ }^{3}$ \\ ${ }^{I}$ Deparment of Laser and Optoelectronics Engineering, University of Technology, Baghdad, Iraq. \\ Raghadhanirh@gmail.com \\ ${ }^{2}$ Deparment of Laser and Optoelectronics Engineering, University of Technology, Baghdad, Iraq. \\ 3140048@uotechnology.edu.iq, \\ ${ }^{3}$ Ministry of Science and Technology/ Baghdad,Boshera65@gmail.com
}

\begin{abstract}
$X$-ray is electromagnetic wave pass through all human tissue and show tissue image by black and white, and the explosion for $x$ ray in short treatment may cause cancer, Photonic crystal fiber used as detector for $x$ - ray approximate effective radiation dose for human bone for spine $x$ - ray $1.5 \mathrm{mSv}$ which need 6month to repeat the exposure and extremity (foot, hand and etc.) $x$-ray $0.001 \mathrm{mSv}$ need to 3 hours to repeat exposure, the change in $x$ ray dose can be detected by measuring the change in wavelength shifting of laser 450nm which pass through photonic crystal fiber and effected by the emission of $x$-ray to record the small change in $x$-ray dose and save the human from radiation and this sensor is small compact and easy to use and have high sensitivity for $x$-ray used to measure the bone $x$-ray as its value lower than other $x$-ray used in others tissue.
\end{abstract}

Index Terms - photonic crystal fiber, sensor, $x$ - ray, laser.

\section{INTRODUCTION}

$\mathrm{X}$-ray is an electromagnetic emission pass through all solid objects such as the human body, it is used in the medical branch for images of the bone and the other structure in the body depending on the object density. The objects with small density produce shadow or dark color because all $\mathrm{x}$-ray passes through it while in material with high density absorb some of the $\mathrm{x}$-ray and some other pass through it so its produce as white in an x-ray image, the absorption of the human body for some of this $\mathrm{x}$-ray called $\mathrm{x}$-ray radiation dose which depends on the amount of radiation absorbed by the human body and there is approximate effective radiation dose [1]. From this important comes for design sensor for the $\mathrm{x}$-ray to save the human body from an increase in $\mathrm{x}$-ray radiation dose as its increase risk in the human body [2,3]. Photonic crystal fiber PCF solid core is a spatial type of fibers used as a sensor for medical application as it detects for x-ray emission with different approximate effective radiation dose, its type from optical fiber but its design consist of solid core in its center and surrounded by cladding with small cores contain air only, this type of fiber called photonic crystal fiber which it has a high sensitivity for material cover it or full its cores even the laser diode wavelength effect by $\mathrm{x}$-ray radiation from that design of sensor come[4,5].

\section{EXPERMENT}

The work was carried out in computer program comsol multiphysics 5.5 which its simulation program used to design photonic crystal fiber PCF large mode area LMA_10 of solid-core photonic crystal fiber surrounded by cladding as an array of cores full with air as in Fig.1. This model made from the material of silica as in LMA_10 large mode area of photonic crystal fiber datasheet used silica as in the Fig.2 while all cores in cladding were full of air as in Fig.3. The laser diode was used Received 2/7/2020 Accepted 22/10/2020 
as a light source and the wavelength in the blue region used with wavelength $450 \mathrm{~nm}$ to sense the effect of the x-ray on the wavelength of the laser [6].

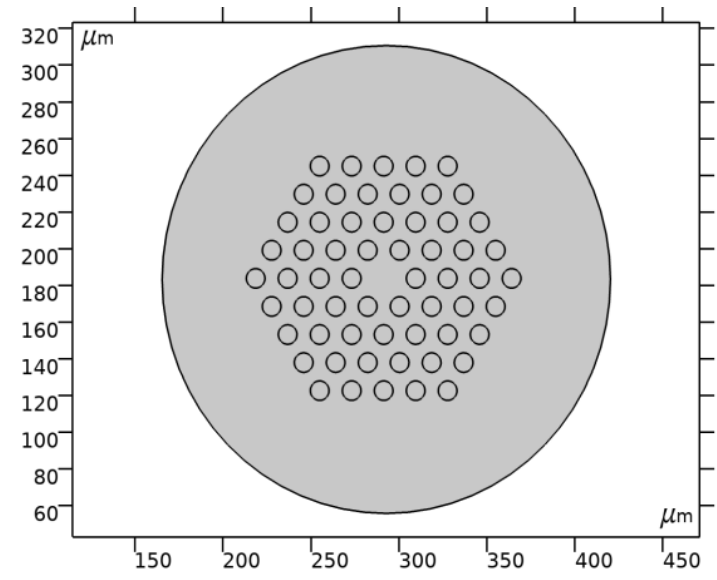

FIG 1. SHOW PHOTONIC CRYSTAL FIBER SOLID CORE WITH CLADDING RADIUS $127.5 \mu \mathrm{m}$ AND CORE RADIUS 5.3 $\mu \mathrm{M}$, PCF SURROUNDED BY SQUARE

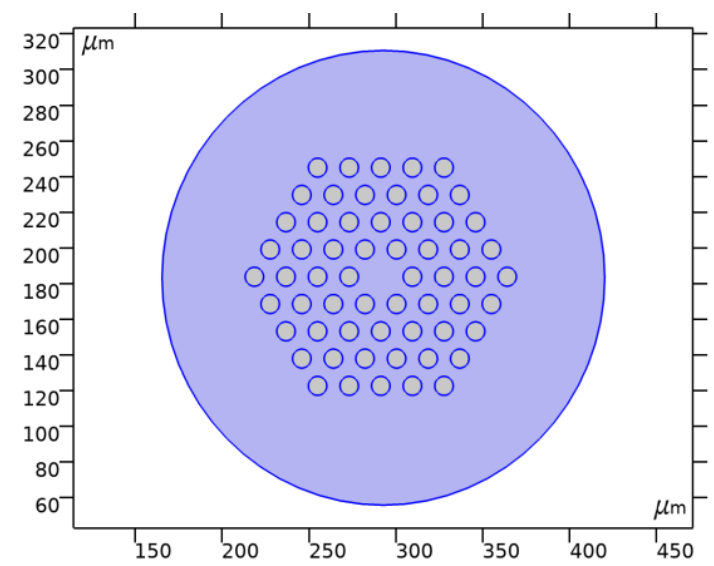

FIG 2. SHOW PHOTONIC CRYSTAL FIBER MATERIAL (SILICA)

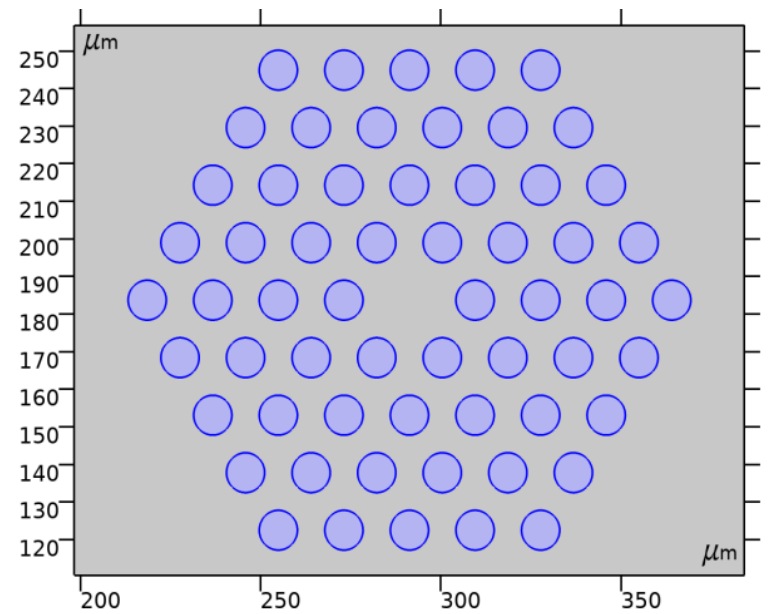

FIG 3. SHOW PHOTONIC CRYSTAL FIBER ITS CORES FULL WITH AIR ONLY

The detector was used to measure the shifting $\mathrm{g}$ in wavelength that results from the effect of $\mathrm{x}$-ray as there are two values. 
Spine $\mathrm{x}$-ray dose for bone is $1.5 \mathrm{mSv}$ (foot, hand and etc.) and extremity $\mathrm{x}$-ray $0.001 \mathrm{mSv}$ for teeth, where each one of this value produce effect on the wavelength of laser and causing shifting in wavelength after its compare with the wavelength graph without the effect of $\mathrm{x}$-ray, the photonic crystal fiber PCF mesh shown in Fig.4 to describe the meshing lines after implying all the external and internal effects for electromagnetic effects in program to simulate the practical situation, because in comsol multiphysics 5.5 all the effects are apply starting from applying the design of photonic crystal fiber and applying all the material after take all the dimensions and material of photonic crystal fiber from datasheet of large mode area photonic crystal fiber LMA_10, then applying all the electromagnetic effects that photonic crystal fiber will effected by it and show the path of laser passing through it to calculate the results by comparing between photonic crystal fiber wavelength shifting before and after applying x-ray, mesh of all effect can be seen in lines mesh as in Fig.4.

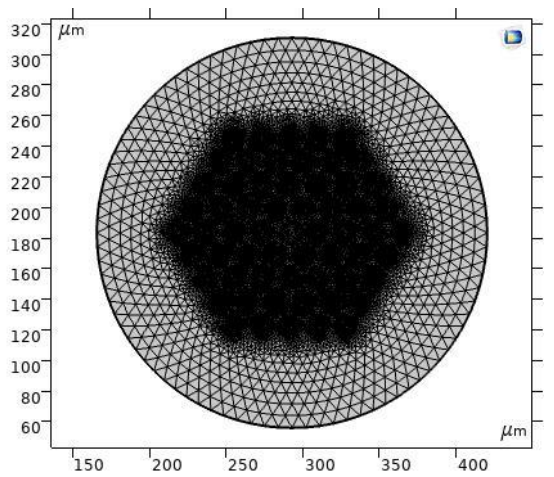

FIG 4. SHOW PHOTONIC CRYSTAL FIBER MESH LINES

\section{RESULTS}

The results will be as a graph for wavelength shifting which it compares the results before and after applying $\mathrm{x}$-ray approximate effective radiation dose for spin $\mathrm{x}$-ray $1.5 \mathrm{mSv} 0$ and extremity $\mathrm{x}$-ray $0.001 \mathrm{mSv}$, to see the power distribution and the wavelength effect which occur when applying $\mathrm{x}$-ray and change its dose concentration as seen in Fig.5 Laser Beam Distribution Inside Pcf Before Applying X-Ray and Fig.6 Show The Laser Beam Distribution In Pcf When X-Ray Appling

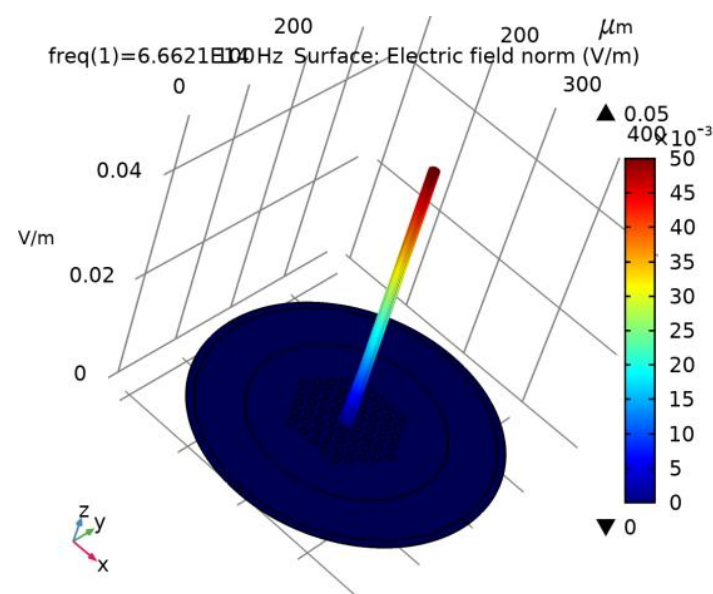

FIG 5. SHOW THE LASER BEAM DISTRIBUTION INSIDE PCF BEFORE APPLYING X-RAY 


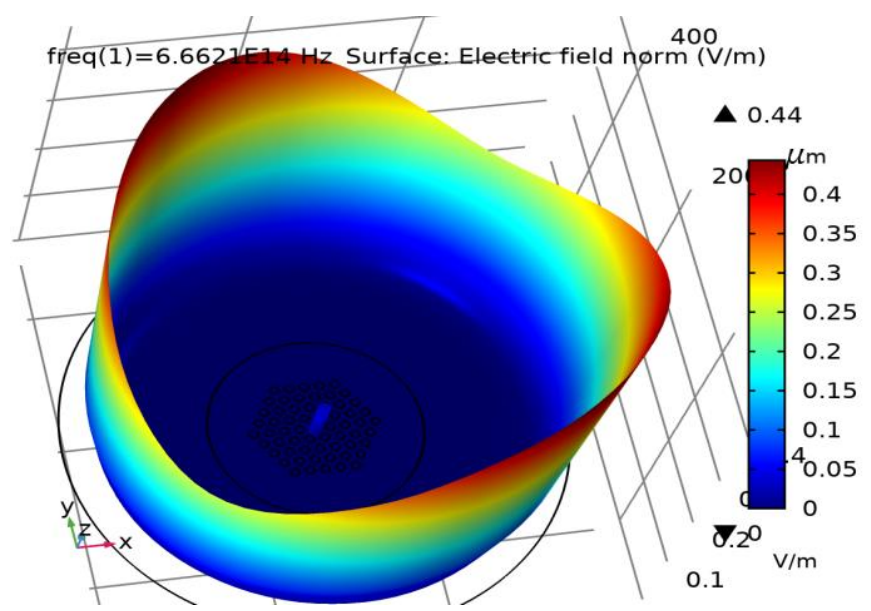

FIG 6. SHOW THE LASER BEAM DISTRIBUTION IN PCF WHEN X-RAY APPLING

The results of both Fig.5 and Fig.6 shows the laser output before x-ray effect and in x-ray effect as output, while the wavelength shift in $\mathrm{nm}$ and power distribution in $\mathrm{mW}$ effect will be as seen in Fig.7 without x-ray effect.

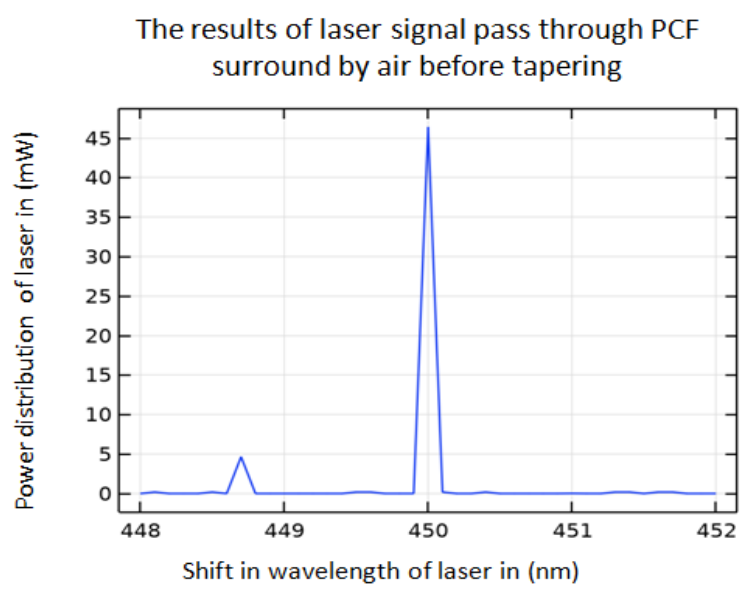

FIG 7. SHOW THE WAVELENGTH PROPAGATION IN X-AXIS AND ITS POWER DISTRIBUTION IN Y-AXIS BEFORE APPLYING X-RAY

Slop $=\frac{x 3-x 2}{y 3-y 2}=0.87 \mathrm{~nm} / \mathrm{mSv}$

Which it describes the sensitivity of this device $0.87 \mathrm{~nm} / \mathrm{mSv}$ by taken the slop.

Fig.8 show the results of laser pass through PCF with X-ray apply $0.001 \mathrm{mSv}$ the approximate effective dose, in Fig.9 the results show the effect of X-ray with approximate effective dose about $1.5 \mathrm{mSv}$, Fig.8 and Fig.9 show the wavelength of laser effect and shifted towards the red shift as X-ray applies and the increase in X-ray dose cause increase in red shift. While in the Fig.10 show the results of the three measured values (without using x-ray and with two values of x-ray) that the relationship is inverted each concentration of dose increase the power level effected and drop for the laser beam and the wavelength shifter redshift [5], the slop between both x-ray dose and wavelength of the laser as the dose increase the shift of wavelength increase to redshift [5]. Another advantage is the small change in $\mathrm{x}$-ray dose can be detected as the $\mathrm{x}$-ray effect. 


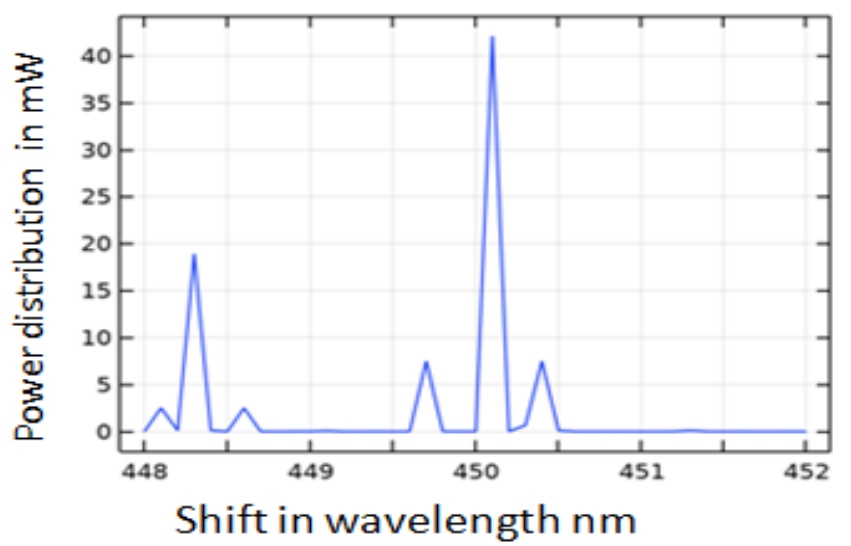

FIG 8. SHOW THE WAVELENGTH PROPAGATION IN X-AXIS AND ITS POWER DISTRIBUTION IN Y-AXIS AFTER APPLYING X-RAY 0.001MSV

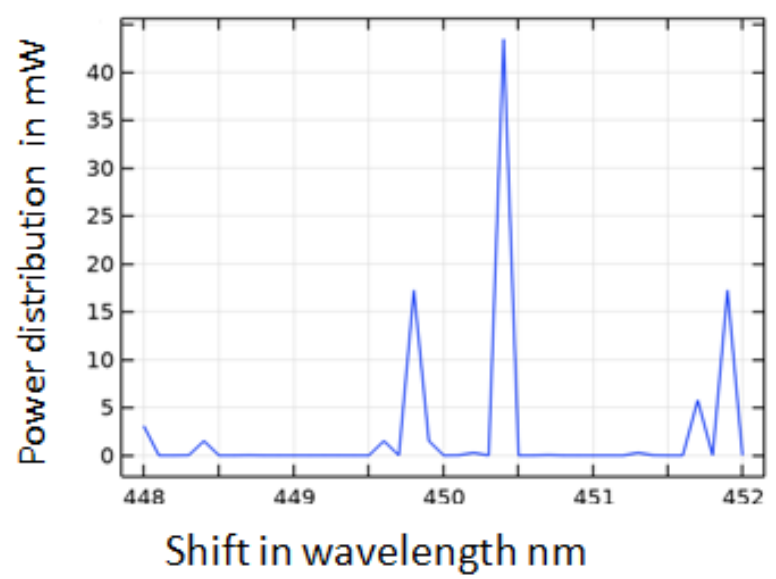

FIG 9. SHOW THE WAVELENGTH PROPAGATION IN X-AXIS AND ITS POWER DISTRIBUTION IN Y-AXIS AFTER APPLYING X-RAY 1.5 MSV
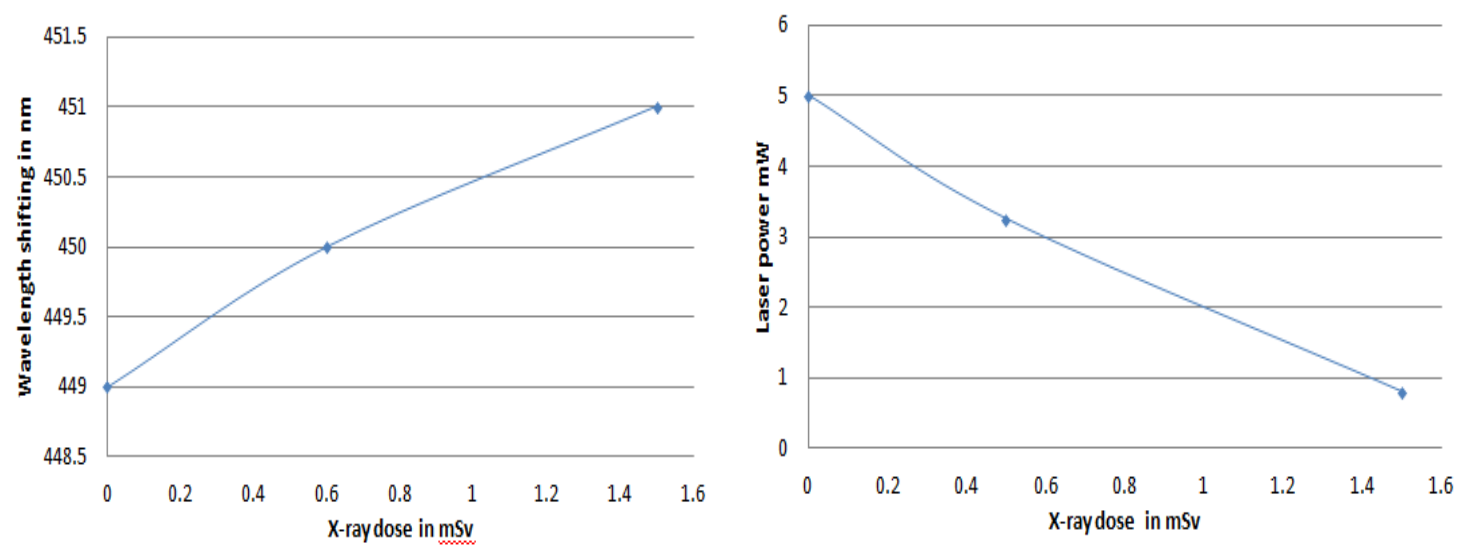

FIG 10. SHOW THE RELATION BETWEEN LASER SHIFTING WAVELENGTH $\triangle \Lambda$ AND X-RAY DOSE WITH BOTH CASE OF X-RAY AND WITHOUT X-RAY 


\section{DISCUSSION}

$\mathrm{X}$-ray is an electromagnetic pass through all solid object and its effect risky if the human got high dose so photonic crystal fiber PCF is used as a sensor for $\mathrm{x}$-ray emission with different dose[7,8,9], from the results its clear that the power is effected of the laser beam and drop while its wavelength is shifted towards redshift, the effect of the x-ray on laser beam inside PCF cause shifting in wavelength of the laser in both case $0.001 \mathrm{mSv}$ and $10 \mathrm{mSv}$. This study moves the science forward as this sensor detects all doses for x-ray in this case in the human past from the place that he doesn't know if there is $\mathrm{x}$-ray inside the building rooms and then he will not be affected by $\mathrm{x}$-ray emission.

\section{CONCLUSION}

The obtained results led to producing a sensor with high sensitivity compare to the traditional sensors as its compact and small size even its accuracy is high because small centimeters of photonic crystal fiber can be used as a sensor to measure any change in its wavelength shifting by applying $\mathrm{x}$ ray and this device easy to use as its need only for laser passing and its made is so easy compared with others $\mathrm{x}$-ray detectors designs and its price will be cheaper as its take only $2 \mathrm{~cm}$ of its length and this open rood for the other researcher to used other photonic crystal fiber lengths to find the effect of sensitivity with the length of photonic crystal fiber [10-15]. The principle from this work is to make a sensor for $\mathrm{x}$-ray emission to protect the human body from the radiation of $\mathrm{x}$-ray as its risky for human health to protect for high doses of $\mathrm{x}$-ray, many research was done before to study the effect of the $\mathrm{x}$ ray on laser diode beam and from that work our idea and work started, comsol multiphysics is a computer program used to stimulate the practical situation for all elements and all effects.

\section{REFRENCES}

[1] N.A.N Khidir1, M.Yousef1, 2, M.A. A. Omer1, 2, M. Gameraddin. A. A. M, "A Review Study on Patient's Radiation Dose from Diagnostic Radiography", International Journal of Science and Research (IJSR), India Online ISSN pp. 2319-7064. 2013

[2] F. Kavaler, R S. Alexander"Risk Management in Healthcare Institutions: Limiting Liability and Enhancing Care",Jones \& Bartlett Publishers, pp. 336-346. 2014

[3] L.Prashanth, K.Kattapagari ,R. Chitturi,V. Baddam,L. Prasad. A review on role of essential trace elements in health and disease. J. NTR Univ Health Sci, pp. 75-85, 2015.

[4] A.Z.Mohammed" photonic crystal fiber mach zehnder interferometer $\mathrm{pH}$ sensing" AIP conference proceedings , pp 1-10, 2018.

[5] N. A. Salman H. J. Taher and S.A. Mohammed, Tapered Splicing Points SMF-PCF-SMF Structure based on Mach-Zehnder interferometer for Enhanced Refractive Index Sensing, 2017.

[6] H. Okuyama, T. Miyajima ,Y. Morinaga, F. Hiei, M. Ozawa, K. Akimoto "ZnSe/ ZnMgSSe blue laser diode",IEEE, Electronics Letters, Volume: 28 , Issue: 19, 10 Sept. 1992.

[7] F.Poil, A.Cucinotta, S.Selleri" photonic crystal fiber properties and application.Springer, 2007.

[8] D. E. Johnson,D.E.Comman, Southwest Research Institute , Health Implications of Sewage Treat. Fan, Da-Jeng Yao, Yi-Chung Tung Optofluidics 2015 ,published in Micromachines,2018.

[9] J. Villatoro, V. Finazzi, G. Badenes and V. Pruneri, "Highly Sensitive Sensors Based on Photonic Crystal Fiber Modal Interferometers" Journal of Sensors, Spain, , pp. 1-11, 2009.

[10] N.A.Salman and H.J. Taher "Refractive index sensor based on a solid-core photonic crystal fiber interferometer", January . pp. 99-105, 2017

[11] A. H. Abdulhadi, S.-j. Qiu, and A. H. Al-Janabi, "DMSO-based photonic crystal f iber sensor with enhanced sensitivity," Chinese Optics Letters. pp1-10, 2014

[12] B. R. Mahdi, A Z. Mohammed and F. F. Ridha, "Micro-structure Chemical Fiber Sensor",Atti della Fondazione Giorgio Ronchi Anno journal LXXII, pp. 250-255, 2016

[13] A. H. Abdulhadi, A.Z.Mohammed, N.H. Numan, R.Hani "THz waves propagation through photonic crystal fiber" International Journal of Innovative Science, Engineering \& Technology, pp. 40-45.2015 
[14] k. Fidanboylu., and H. S. Efendioglu, "Fiber optic sensors and their applications", 5th International Advanced Technologies Symposium (IATS'09, pp. 12-20.2009

[15] A. Z.Mohammed, B. R.Mahdi, L.K.Humdi" Photonic crystal fiber magnetic field sensor based on Ampere Force" Sci.Int.(Lahore),pp.99-102 2017. 